\title{
Pathogenic mechanism of miR-21 in autoimmune lymphoid hyperplasia syndrome
}

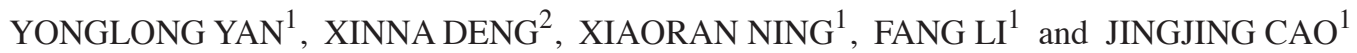 \\ Departments of ${ }^{1}$ Rheumatology and ${ }^{2}$ Medical Oncology, \\ Hebei Province General Hospital, Shijiazhuang, Hebei 050051, P.R. China
}

Received July 21, 2016; Accepted January 19, 2017

DOI: $10.3892 / \mathrm{ol} .2017 .6039$

\begin{abstract}
R-21 plays an important role in immune responses and inflammatory diseases, but the mechanism of action of miR-21 in autoimmune lymphoid hyperplasia syndrome still remains unclear. The aim of the present study was to assess the mechanism of miR-21 in autoimmune disease, particularly, the autoimmune lymphoid hyperplasia syndrome. The pathology and immunity-related phenotypes of miR-21 transgenic mice, and the lymphocyte subsets were analyzed. The related $\mathrm{T}$ cell subsets and germinal center B (GCB) cells generated at the germinal center were detected with flow cytometry. The target genes of miR-21 were evaluated with the luciferase reporter gene method. The homeostatic proliferation of the lymphocytes was detected with the EdU incorporation assay. Inflammatory infiltration occurred to the lung and liver of the transgenic mice at 8 weeks. The frequency of the regulatory helper T cells decreased slightly. Significantly increased double negative $\mathrm{T}$ cells were observed in the spleen of the transgenic mice $(\mathrm{P}<0.05)$. The immunoglobulins IgG1, IgG2a, $\operatorname{IgG} 2 \mathrm{~b}$, and $\operatorname{IgG} 3$ in the serum of the transgenic mice aged 8 weeks were significantly higher than those in the wild-type mice aged 8 weeks $(\mathrm{P}<0.05)$. The percentages of the GCB cells in the peripheral lymphoid organs such as lymph nodes, mesenteric lymph nodes, PP and spleen in the transgenic mice aged 8-52 weeks increased significantly $(\mathrm{P}<0.05)$. The percentage $(26.32 \%)$ of the newly-formed GCB cells derived from transgenic mice was significantly higher than that $(3.87 \%)$ of the GCB cells derived from the wild-type mice. miR-21 played a role of negative feedback regulation by inhibiting the $\mathrm{NF}-\kappa \mathrm{B}$ signal pathway. The highly-expressed miR-21 B cells promoted homeostatic proliferation of the T cells. miR-21
\end{abstract}

Correspondence to: Dr Yonglong Yan, Department of Rheumatology, Hebei Province General Hospital, 348 West Heping Road, Shijiazhuang, Hebei 050051, P.R. China

E-mail: yonglongyan160530@163.com

Key words: miR-21, autoimmune lymphoid hyperplasia syndrome, Fas, B cells at the germinal center, homeostatic proliferation can promote homeostatic proliferation of lymphocytes by inhibiting the $\mathrm{NF}-\kappa \mathrm{B}$ signal pathway.

\section{Introduction}

Several studies have demonstrated that miR-21 has different expression profiles in various hematopoietic cells (1). Low levels of miR-21 were reported in naive $\mathrm{T}$ cells, while in regulatory helper $\mathrm{T}$ cells (Treg) this level was reported as high (2). High expression of miR-21 also occurs in memory and effector T cells, and miR-21 expression is significantly upregulated after being stimulated by the $\mathrm{T}$ cell receptor (TCR) (3). High levels of miR-21 have been observed in Th1 cells, but miR-21 expression in Th2 cells is stronger. Low levels of miR-21 expression have been reported in precursor $B$ cells and progenitor B cells but germinal center B (GCB) has been shown to express high levels of miR-21 (4). miR-21 can serve as a negative feedback control factor in innate immunity (5).

In the human mononuclear cell line, when LPS stimulates THP-1 cells miR-21 expression is quickly upregulated via the toll-like receptor (6). Prior reports showed that LPS, IL-1 $\alpha$ and TNF- $\alpha$ can induce miR-21 expression via NF- $\kappa \mathrm{B}(7)$. $\mathrm{NF}-\kappa \mathrm{B}$ activation increases the expression of miR-21, while miR-21 reduces the $\mathrm{NF}-\kappa \mathrm{B}$ activity by downregulating TRAF6 and IRAKl $(8,9)$. The negative feedback mechanism of miR-21 plays an important role in physiological and pathological processes in innate immunity, virus infection and tumorigenesis. miR-21 also plays an indispensable role in acquired immunity. In activated T cells, miR-21 inhibits cell death induced by activation of $\mathrm{T}$ lymphocytes and inhibits production of IL-2 (10). miR-21 also plays an important role in peripheral immune tolerance of Treg (11), and miR-21 has been found to be implicated in autoimmune diseases such as rheumatoid arthritis (RA) $(11,12)$. In joint synovial tissue of RA patients, the level of miR-21 has been reported to be significantly higher compared to synovial tissue in osteoarthritis patients. Additionally, it was reported that in vitro stimulation of joint synovial cell cultures obtained from RA patients with TNF- $\alpha$ and IL- $1 \alpha$, increased miR-21 expression level (13). Autoimmune lymphoproliferative syndrome (ALPS) also known as Canale-Smith syndrome is caused by excess hyperplasia of lymphocytes due to apoptosis disorders (14). ALPS is a rare disease caused by lymphocyte 
proliferation due to programmed death of lymphocytes or apoptosis disorders (15).

To better study the pathological and physiological significance of miR-21, we investigated the biological functions of miR-21 in ALPS and revealed a mechanism different from inflammation negative feedback. It provides a new explanation for pathogenesis of ALPS.

\section{Materials and methods}

Experimental animals. Healthy SPF male C57b6/L mice aged 6-8 weeks (Laboratory Animal Center, Hebei Medical University, Shijiazhuang, China; laboratory animal license no. SCXK 2015-0004) and miR-21 gene knockout mice (Jakson Laboratory, CA, USA; laboratory animal no. 016856), weighing 20-25 g were used in the present study. Mice were divided into two groups: i) The wild-type group (WT) and ii) the transgenic group (TG). Approval for the animal experiments was received from the Animal Ethics Committee of Hebei Province General Hospital.

\section{Experimental methods}

$R T$-polymerase chain reaction (PCR). Heart, liver, lung, kidney, spleen, and lymph node tissues were extracted from mice in both groups. TRIzol $(1 \mathrm{ml})$ was added to $5 \mathrm{mg}$ of each sample and after mixing, samples were left for $5 \mathrm{~min}$ at room temperature. Chloroform was added ( $1 / 5$ volume) to the sample and mixed well for $1 \mathrm{~min}$ and left at room temperature for $5 \mathrm{~min}$. Sample was then centrifuged for $15 \mathrm{~min}$ at $10,000 \mathrm{xg}$ at room temperature.

Equal volume of isopropanol was then added and mixed gently by turning the tube upside down. After $10 \mathrm{~min}$ at room temperature, sample was centrifuged for $10 \mathrm{~min}$ at $10,000 \mathrm{xg}$ at $4^{\circ} \mathrm{C}$. Supernatant was discarded and $1 \mathrm{ml}$ of $75 \%$ ethyl alcohol was added to the pellet. Appropriate amount of DEPC was dissolved in water and precipitated. The reaction system was $25 \mu \mathrm{l}$ including fluorescence RT-PCR reaction liquid $(20 \mu \mathrm{l})$, DNA polymerase-I $(1 \mu \mathrm{l})$, reverse transcriptase $(0.35 \mu \mathrm{l})$, and template RNA $(5 \mu \mathrm{l})$. They were mixed and centrifuged for $10 \mathrm{sec}$ at 5,000 x g.

Real-time fluorescence RT-PCR amplification process was as follows: Reverse transcription for $30 \mathrm{~min}$ at $50^{\circ} \mathrm{C}$; pre-denatured for $3 \mathrm{~min}$ at $95^{\circ} \mathrm{C}$; denatured at $95^{\circ} \mathrm{C}$ for $15 \mathrm{sec}$, annealed for $30 \mathrm{sec}$ at $50^{\circ} \mathrm{C}$, extended for $30 \mathrm{~min}$ at $72^{\circ} \mathrm{C}$, 5 cycles in total; denatured for $10 \mathrm{sec}$ at $95^{\circ} \mathrm{C}$; annealed for $40 \mathrm{sec}$ at $55^{\circ} \mathrm{C}, 45$ cycles in total.

$H \& E$ staining and immune histologic chemical staining. Paraffin sections of the heart, liver, lung, kidney, spleen, and lymph node tissues were routinely dewaxed. Sections were incubated with $3 \% \mathrm{H}_{2} \mathrm{O}_{2}$ methanol solution for $10 \mathrm{~min}$ at room temperature to block the endogenous peroxidase. Sections were rinsed 3 times with PBS, repaired for $8 \mathrm{~min}$ at high temperature using $0.01 \mathrm{~mol} / \mathrm{l}$ citrate buffer solution ( $\mathrm{pH}$ 6.0), cooled to the room temperature, and rinsed with PBS 3 times (5 min each). Some sections were stained using $\mathrm{H} \& \mathrm{E}$ and the remaining sections were blocked for $30 \mathrm{~min}$ at $37^{\circ} \mathrm{C}$ after dropwise addition of goat serum operating fluid. After dropwise addition of PNA (1:200) (Sigma-Aldrich, St. Louis, MO, USA), they were allowed to stand overnight at $4^{\circ} \mathrm{C}$ and rinsed with PBS 3 times (5 min each). After dropwise addition of biotinylated goat anti-rabbit second antibody operating solution (cat no. P0203; Boster Inc., Wuhan, China), sections were incubated for $20 \mathrm{~min}$ at $37^{\circ} \mathrm{C}$ and rinsed with PBS 3 times ( 5 min each). After addition of horseradish peroxidase-marked streptavidin operating liquid, the sections were incubated for $20 \mathrm{~min}$ at $37^{\circ} \mathrm{C}$ and rinsed with PBS 3 times (5 min each). Sections were then developed with DAB, re-stained with hematoxylin and differentiated with $0.1 \%$ hydrochloric ethanol. Samples were then immersed in tap water, dehydrated, clarified, and mounted with neutral resin.

Analysis of serum immunoglobulin $(\operatorname{Ig} G)$ concentrations and types. MILLIPLEX MAP Mouse IgG Isotyping Magnetic Bead Panel, MGAMMAG-300K (both from Biosharp, Hefei, China) were used. We used IgG (1, 2a, 2b, and 3), IgM, and IgA (diluted at 1:25,000) following the protocol reported by Ruan et al (16).

Flow cytometry. Mice were sacrificed and spleen, lymph node, mesenteric lymph nodes, PP globule, and thymus gland were extracted and placed in pre-cooled cell culture media. Two mouse thigh bones were taken and both ends were cut out. A $1 \mathrm{ml}$ syringe was used to draw 5\% FBS buffer solution (Gibco-BRL, Grand Island, NY, USA) and the red marrow was flushed twice. In order to prepare single-cell suspension, red blood cell lysis buffer was added to spleen and bone marrow to remove red blood cells. Cell counts were performed and cell concentration was adjusted to $1 \times 10^{6} / 100 \mu 1$. Index antibody was then added and transferred to ice-bath and incubated for $\geq 45$ min away from light. Mouse monoclonal antibodies, such as anti-CD95/Fas (dilution, 1:100; cat. no. 15A7), anti-CD38 (dilution, 1:100; cat. no. 90), anti-CD3 (dilution, 1:100; cat. no. 17A2), anti-CD4 (dilution, 1:100; cat. no. RM4 5), anti-CD4 (dilution, 1:100; cat. no. GK1.5), anti-CD44 (dilution, 1:100; cat. no. IM7), anti-CD62L (dilution, 1:100; cat. no. MEL 14), anti-CD25 (dilution, 1:100; cat. no. PC61.5), anti-CD69 (dilution, 1:100; cat. no. H1.2F3) and anti-B220/CD45R (dilution, 1:100; cat. no. RA3 6B2) were all purchased from eBioscience (San Diego, CA, USA). FlowJo (Tree Star, Inc., Ashland, OR, USA) was used for data analysis.

Adoptive transfer. The flow cytometer FACSAria II (BD Biosciences) was used to sort out the non-GCB cells. The resulting cells were washed once with cell culture medium and stabilized for $1-2 \mathrm{~h}$ in a culture flask for subsequent experiments. Non-GCB cells $\left(1 \times 10^{6}\right)$ and CD4 ${ }^{+} \mathrm{T}$ cells $\left(1 \times 10^{6}\right)$ were mixed (1:1). Cell suspension was injected into the immunodeficiency SCID mice via the caudal vein without any spillage (17). The percentage of the newly-generated GCB cells from the donor and the expression of Fas in the newly-generated GCB cells were measured at 7 days after adoptive transfer.

Homeostatic proliferation test. Click-iT ${ }^{\circledR} \mathrm{EdU}$ cell proliferation assay was used. A $200 \mu \mathrm{l} \mathrm{EdU} \mathrm{(500} \mu \mathrm{g} / \mathrm{ml}$; KeyGene Biotech, Nanjing, China) was injected peritoneally at 24 days after adoptive transfer and strengthened every $48 \mathrm{~h}$ and mice were sacrificed at day 7 . To complete the test, we followed the instructions provided by the kit's manufacturer (18). The surface marker was B220 or CD4 and cells were routinely 
A

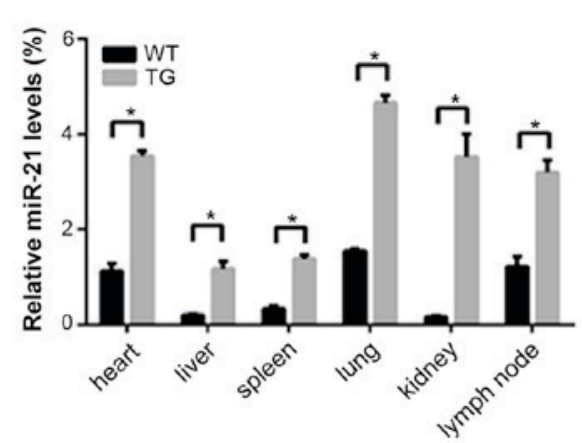

C

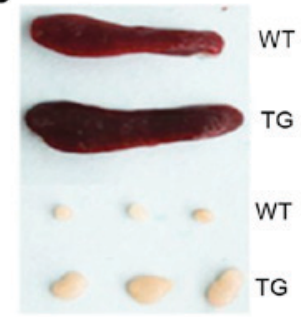

D

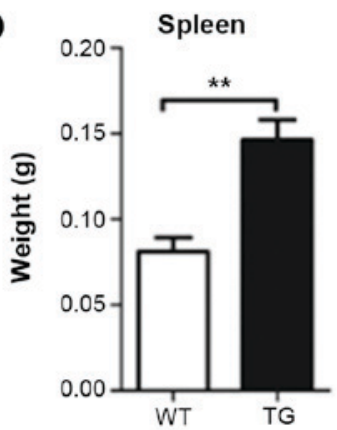

B

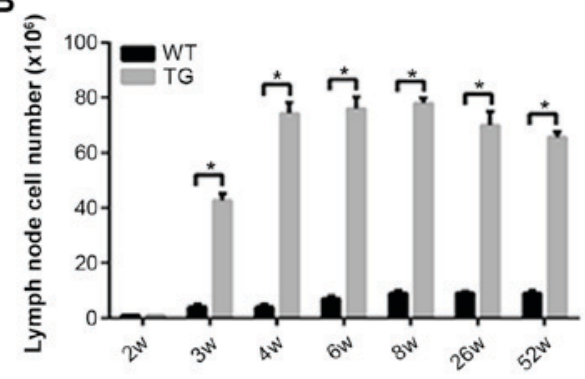

E

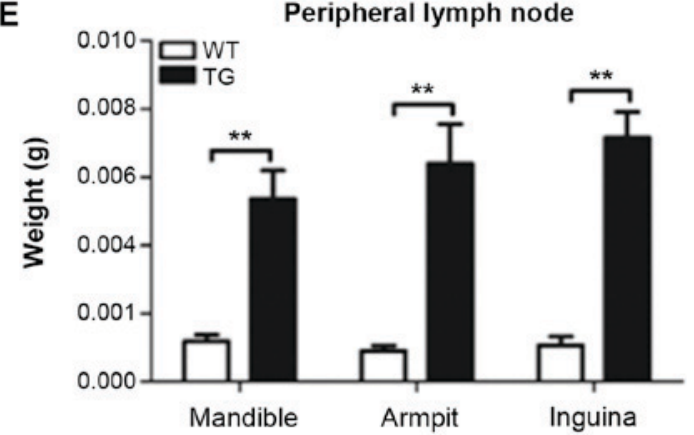

F
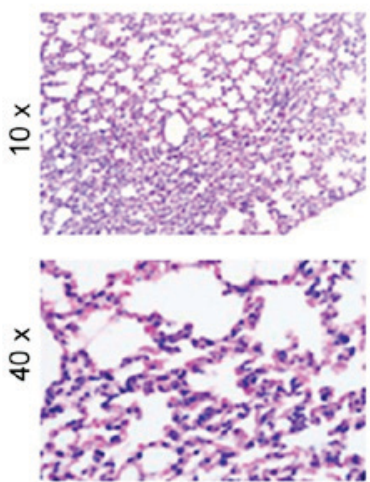

WT
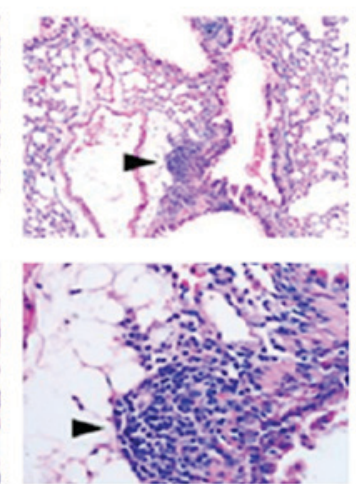

TG
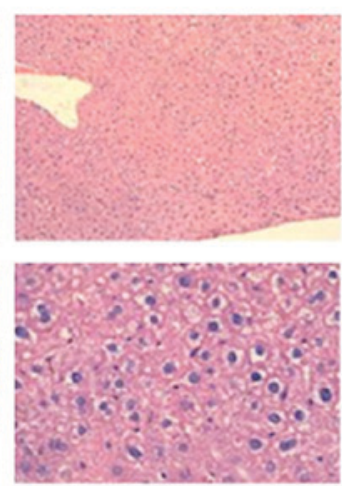

WT
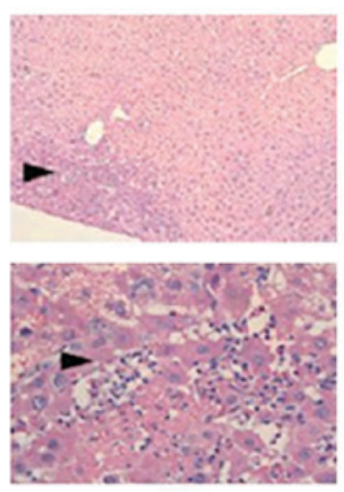

TG

Figure 1. General characteristics of miR-21 gene knockout mice. (A) Expression of miR-21 in various visceral organs in miR-21 transgenic mice was subjected to fluorescent quantitative polymerase chain reaction detection. (B) The expression levels of miR-21 in the spleen and lymph node were significantly higher than those in the wild-type control mice at the same age. (C) The volume of the lymph node in transgenic mice was 3 times larger than wild-type mice at 3 weeks after birth, 8 times at 4 weeks after birth, and approximately 4 times at 6 weeks. (D) Based on the pathologic analysis of heart, liver, spleen, lung, and kidney, it was found that inflammatory cell infiltration occurred in lung and liver of 8-week old transgenic mice. (E) Weight of peripheral lymph node in WT and TG mice. ${ }^{*} \mathrm{P}<0.05,{ }^{* *} \mathrm{P}<0.01$. (F) H\&E staining in lung and liver tissues from $\mathrm{WT}$ and TG mice.

stained, incubated, fixed, and permeated. The Click-iTrM EdU test solution was then added and flow cytometer was used to analyze the homeostatic proliferation of the lymphocytes.

Dual-luciferase reporter gene reporting method. The Dual-Luciferase ${ }^{\circledR}$ Reporter Assay kit (KeyGene Biotech) was used. The vector (pZZX-Luc-Fas) of Fas 3'-non-translated region (3'-UTR), miR-146a (pEZX-miR-146), and non-significant control miR-scramble (pEZX-miR-scramble) were extracted and purified following the instructions provided by the kit's manufacturer (19).

Statistical analysis. We used SPSS 19.0 software (IBM, Armonk, NY, USA) for data analysis. Measurement data were presented as mean \pm standard deviation. Dependent t-test was used for intergroup significance comparison. $\mathrm{P}<0.05$ was considered to indicate a statistically significant difference.

\section{Results}

miR-21 gene knockout characteristics. miR-21 expression levels in various visceral organs were measured using quantitative PCR (Fig. 1A). In the TG, miR-21 expression levels in spleen and lymph node were significantly higher than those in the WT at 3 weeks after birth (Fig. 1B). The average lymph node volume in the TG was 3 times larger than that in the WT at 3 weeks after birth. The average volume was 8 times larger at 4 weeks after birth, and $\sim 4$ times larger at 6 weeks (Fig. 1C). In the TG, we detected inflammatory cell infiltration in lung and liver at 8 weeks after birth (Fig. 1D).

miR-21 gene knockout mice exhibiting characteristics of autoimmune lymphoid hyperplasia syndrome. Results obtained from immunophenotyping showed that in the TG, the number of $\mathrm{T}$ cells in thymus gland was at normal level (Fig. 2A-C). 
A

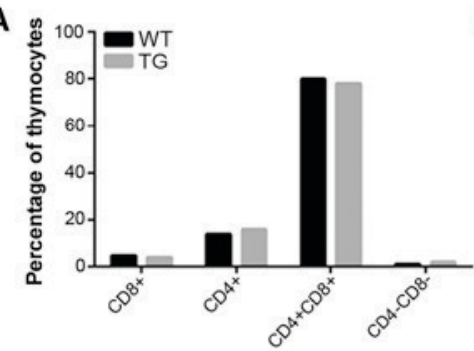

$\mathrm{D}$

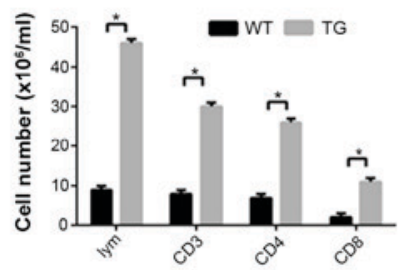

G

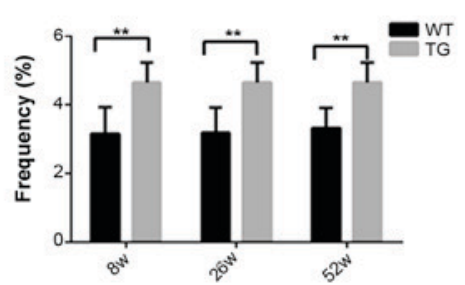

B

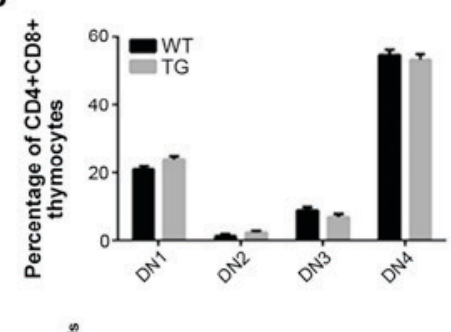

$\mathrm{E}$

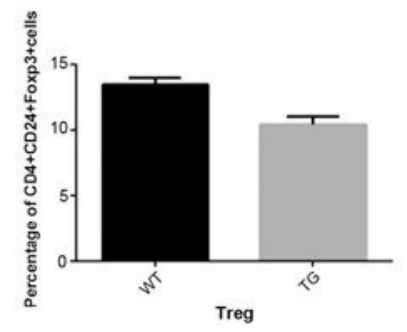

$\mathrm{H}$

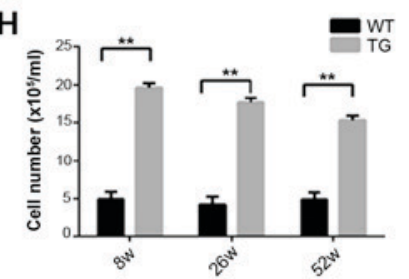

C

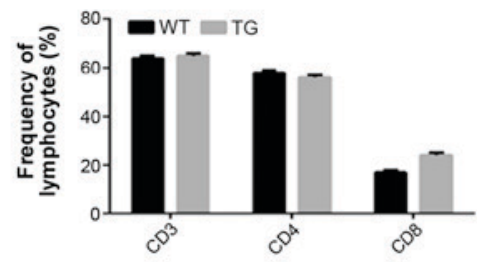

$\mathbf{F}$
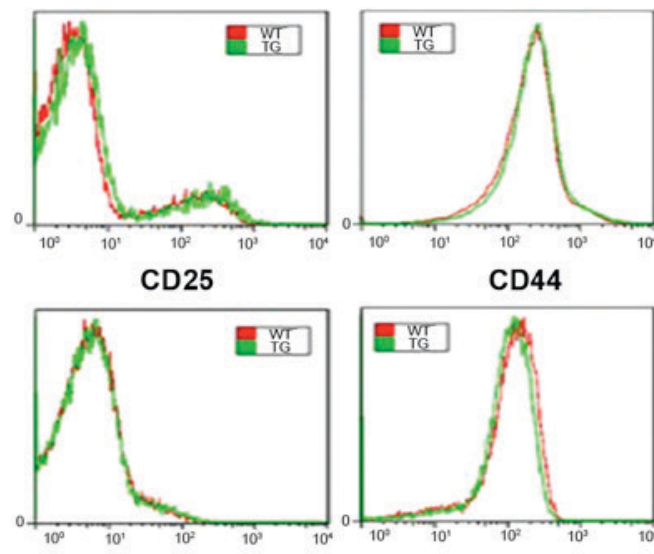

CD44

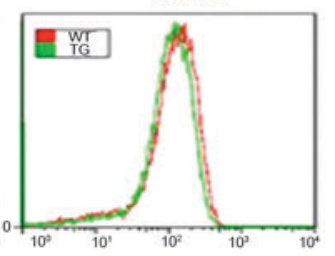

Figure 2. miR-21 gene knockout mice exhibit characteristics of autoimmune lymphoid hyperplasia syndrome. (A-C) T cells in the thymus gland in transgenic mice were normal in general and their impact on various subsets of T lymphocytes was insignificant. The lymphatic node was swollen and the number of various cell subsets increased significantly. (D and E) The frequency of the Treg cells decreased slightly. (F) The surface markers CD25, CD69, CD44, and CD62L of the $\mathrm{CD}^{+} \mathrm{T}$ cells $\left(\mathrm{CD}^{+} \mathrm{T}\right)$ were normal. $(\mathrm{G}$ and $\mathrm{H})$ Based on the frequency and absolute quantity of the DNT cells in the spleen of transgenic mice at 8,26 and 52 weeks. It was found that double-negative $\mathrm{T}$ cells were accumulated in the spleen of the transgenic mice. ${ }^{*} \mathrm{P}<0.05$, ${ }^{* * *} \mathrm{P}<0.01$.

However, the number of various cell subsets increased significantly (Fig. 2D), while the number of other cell types, such as Treg cells decreased slightly (Fig. 2E). Results revealed that the levels CD25, CD69, CD44 and CD62L were at normal levels (Fig. 2F).

In the $\mathrm{TG}$, the percentage of double negative $\mathrm{T}$ cells (DNT) in the spleen increased significantly. CD3 ${ }^{+} \mathrm{CD} 4{ }^{-} \mathrm{CD} 8^{-}$ $\mathrm{TCRaIB}^{+}$served as the surface markers and we detected the frequency and absolute quantity of the DNT cells in the spleen at 8,26 and 52 weeks. It was found that in the transgenic mice, DNT cells were accumulated in the spleen (Fig. 2G and H).

miR-21 gene knockout mice spontaneously collect the germinal center B cells and increasing IgG in serum. The levels of $\mathrm{IgGl}$, $\mathrm{IgG} 2 \mathrm{~b}, \mathrm{IgG} 2 \mathrm{a}$, and IgG3 in the serum of 8-week old transgenic mice were 3-6 times higher than those in the wild-type mice. IgGl and IgG2a serum levels in 52-week old transgenic mice were still higher compared with the wild-type mice, however IgG2b and IgG3 levels were normal in 52-week old transgenic mice (Fig. 3A and B).

In miR-21 transgenic mice, spontaneous germinal center reaction was detected in peripheral lymphoid organs (Fig. 3C), and the proportion of $\mathrm{B}$ cells in the germinal center in the miR-146 transgenic mice was significantly higher than that in the wild-type mice (Fig. 3D and E). Similar results were observed in the mesenteric lymph nodes, PP globules, and spleen (Fig. 3F and G).

miR-21 downregulates the Fas protein expression in $G C B$ cells. Fas protein expression in various subsets of the lymphocytes including $\mathrm{CD} 3^{+} \mathrm{CD} 4^{+} \mathrm{T}$ cells, $\mathrm{CD} 3^{+} \mathrm{CD} 8^{+} \mathrm{T}$ cells, $\mathrm{CD}^{+}{ }^{+} \mathrm{CD} 4^{+} \mathrm{CD} 8$ cells, $\mathrm{TCRaIB}^{+} \mathrm{DNT}$ cells, $\mathrm{B} 220^{+} \mathrm{PNA}^{+} \mathrm{CD} 38^{\text {low }}$ non-GCB cells, B220+PNA and CD $38^{\text {high }}$ GCB cells were evaluated in the transgenic mice, using flow cytometry. High Fas protein expression was only detected in the GCB cell subsets in wild-type mice (Fig. 4A). miR-21 overexpression effectively reduced Fas protein expression in GCB cells. Compared to wild-type mice, the Fas average fluorescence intensity in the GCB cells in the transgenic mice decreased by more than $50 \%$ (Fig. 4B). Our results demonstrated that Fas was the direct target of miR-21 (Fig. 4C).

miR-21 strengthens homeostatic proliferation of lymphocytes. Natural B cells or $\mathrm{CD} 4^{+} \mathrm{T}$ cells from transgenic and wild-type mice were transferred into the SCID recipient mice with immunodeficiency. Homeostatic proliferation of lymphocytes was studied (EdU incorporation assay). Seven days after adoptive transfer, the proliferation level of the natural $\mathrm{B}$ cells originating from the transgenic mice was significantly higher than those B cells originating from the wild-type mice. However, no significant difference was observed in the case of CD4 ${ }^{+} \mathrm{T}$ cells (Fig. 5).

\section{Discussion}

It has been shown that miR-21, miR-132, and miR-155 levels are upregulated when the THP cells are stimulated by LPS. Other reports demonstrated that miR-21 was a $\mathrm{NF}-\kappa \mathrm{B}$-dependent natural immune negative feedback regulatory factor (20), and the major target genes were shown to be 

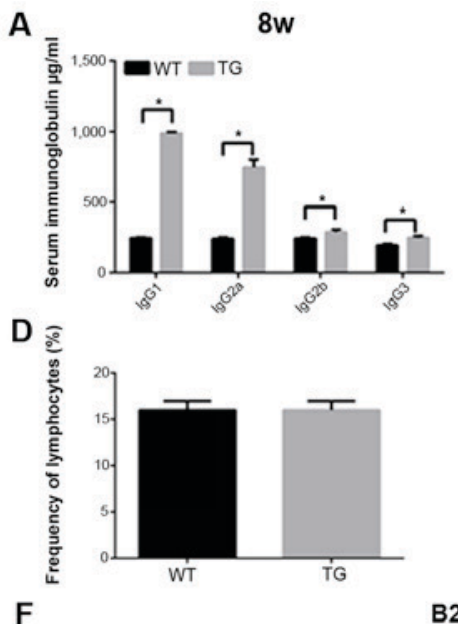

\section{$\mathrm{E}$}
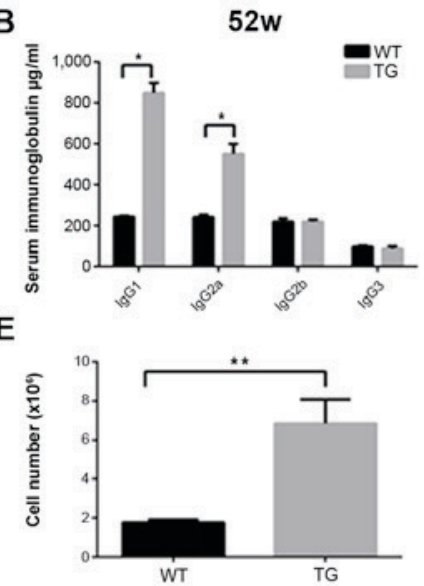

$\mathrm{B220}^{+}$gate

LN

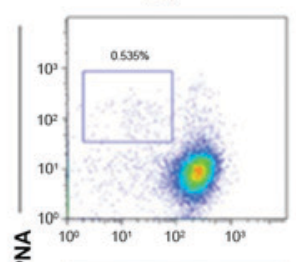

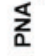

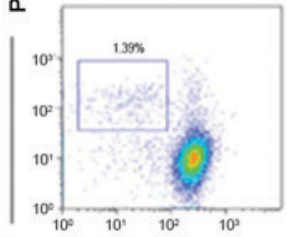

$\mathrm{mLN}$
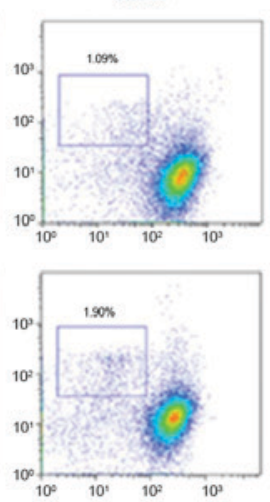

CD38
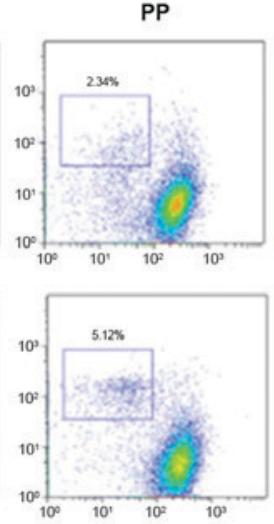

C

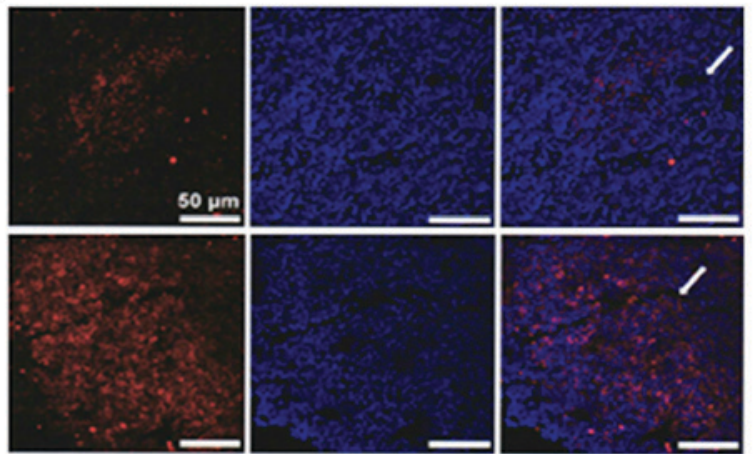

G

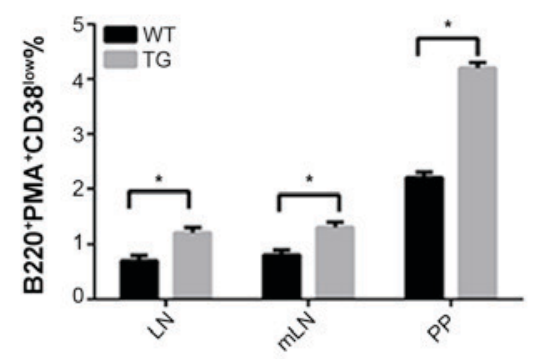

H

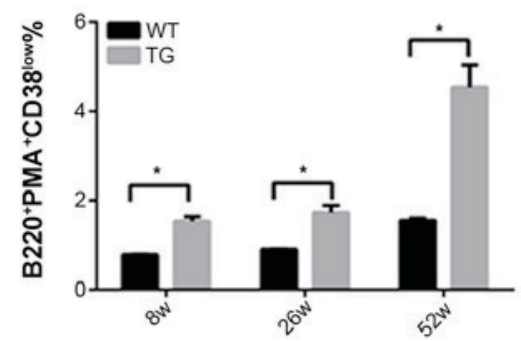

Figure 3. miR-21 gene knockout mice spontaneously collect the germinal center B cells. (A and B) The levels of IgGl, IgG2b, IgG2a, and IgG3 in the serum of 8-week transgenic mice were (3-6 times) higher than that in wild type mice. The levels of IgGl and IgG2a in 52 weeks old transgenic mice were still higher than that in the wild-type mice. (C) Confocal analysis detected spontaneous germinal center reaction in the peripheral lymphoid organs of the miR-21 transgenic mice. (D and E) The proportion of B cells in the germinal center of the lymph node in miR-146 transgenic mice was significantly higher than that in the wild-type mice. (F and G) In miR-146 transgenic mice, the proportion of the germinal center B cells in mesenteric lymph nodes, PP globules, and spleen were significantly higher than those in the wild-type mice. $(\mathrm{H})$ The age of the mice with accumulated GCB cells ranged from 8 to 52 weeks. ${ }^{*}<0.05,{ }^{* *} \mathrm{P}<0.01$.

TRAF6 and IRAK-1/2 (21). It has been reported that, miR-21 gene knockout mice usually suffer from spontaneous autoimmune disorders and die before reaching maturity. Following characteristics were observed in these mice: i) Spleen and lymph node enlargement, ii) inflammatory infiltration in multiple organs, and iii) imbalance in peripheral immune tolerance of $\mathrm{T}$ cells. Moreover, myeloid cell proliferation and peripheral lymphoid organs tumors might occur in these mice.

T cell survival, activation and apoptosis rate in transgenic mice with overexpressed miR-21 were not different compared with wild-type mice. It seems that miR-21 regulates the $\mathrm{T}$ cell mediated immune response via a negative feedback mechanism. TCR transfers the antigen-activated signals to $\mathrm{T}$ cells and the three signal pathways implicated in this induction are: NFAT, AP-1 and NF- $\mathrm{B}$ (22). Imbalance of $\mathrm{NF}-\kappa \mathrm{B}$ in $\mathrm{T}$ cells may lead to immuno-inflammatory responses mediated by $\mathrm{T}$ cells and malignant tumor genesis (23). We detected a large number of DNT cells in the spleen. This observation along with other observations such as enlargement of lymph nodes and spleens and presence of inflammatory cell infiltration in liver and lung were in line with the characteristics of human autoimmune lymphoid hyperplasia syndrome (ALPS).

Although spontaneous ALPS occurred in miR-21 transgenic mice, the majority of ALPS patients may be affected by non-malignant enlargement of lymph nodes and spleen at a tender age. In these cases, the number of DNT cells increased significantly and $\mathrm{IgG}$ level in the serum was considerably elevated (24).

Spleen and lymph gland enlargement is often observed in 3-week old miR-21 transgenic mice and a peak is usually reached at 4 weeks after birth. In all young transgenic mice, we observed an increase in the number of DNT cells in the spleen, while IgGl, IgG2b, IgG2a, and IgG3 levels in 8-week old transgenic mice were higher than those in wild-type mice. These conditions were relieved at 52 weeks. miR-21 transgenic mice had an extremely high morbidity of pulmonary and hepatic inflammatory cell infiltration. Clinically, $4-5 \%$ of the ALPS patients have infiltrative pulmonary lesions and liver dysfunctions.

Genetic defects in typical ALPS patients mainly occur in the apoptosis pathway. These defects directly break the lymphocytes homeostasis and immune tolerance (25). Prior reports have shown that Fas gene mutation and Fas protein 


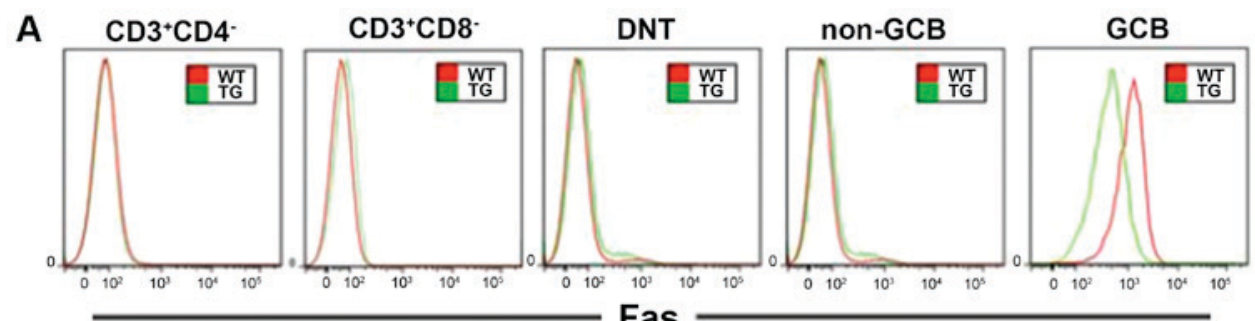

B

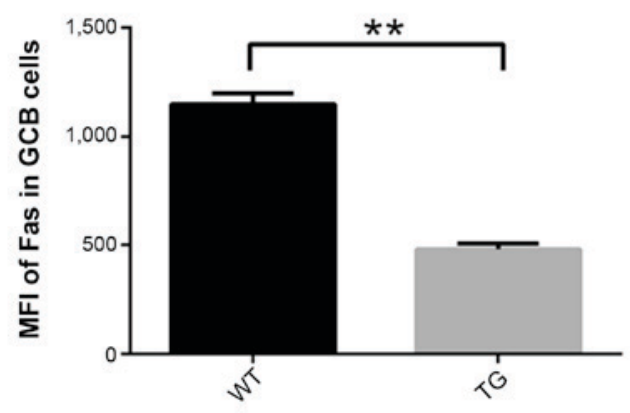

C

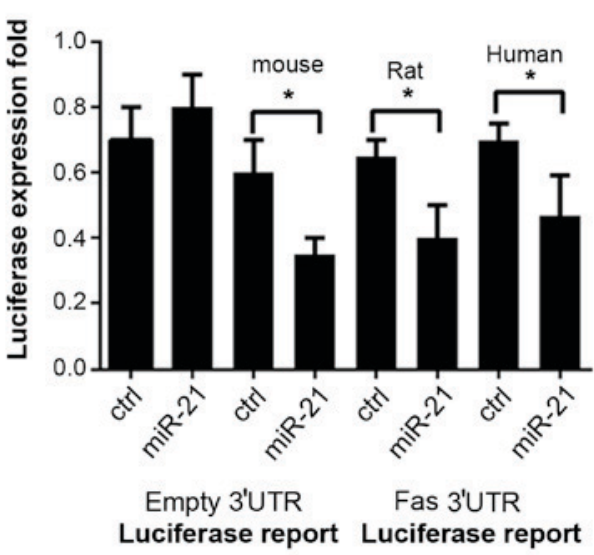

Figure 4. miR-21 downregulates the Fas protein expression in GCB cells. (A) Fas protein was highly expressed in wild-type mice. Overexpression of miR-21 significantly reduced Fas protein expression in GCB cells. (B) In transgenic mouse GCB cells, the Fas fluorescence intensity decreased by $>50 \%$ compared with that in the wild type mice. (C) Bioinformatics comparative analysis: The 3'UTR region in the Fas gene and the appropriate miR-21 seed region were compared among humans, rats, and mice. Among the three species, the fluorescence in the miR-21 plasmid experimental group decreased significantly compared with that in the control plasmid group. ${ }^{*} \mathrm{P}<0.05,{ }^{* * *} \mathrm{P}<0.01$.

A

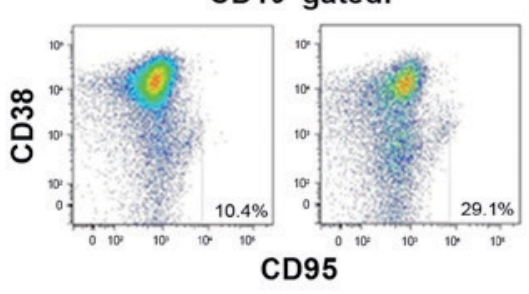

C

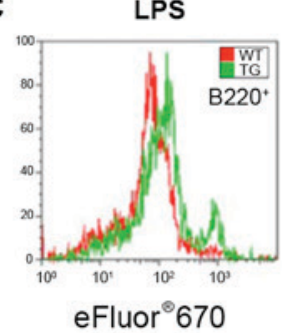

CD19+ gated:

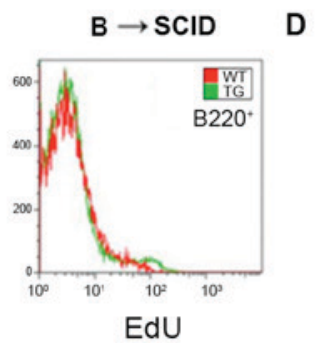

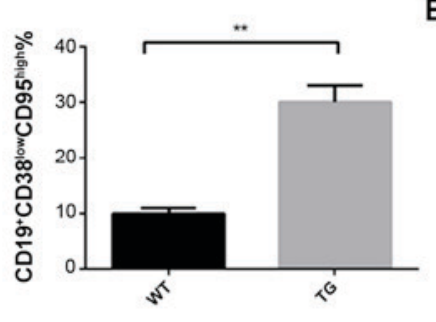

D

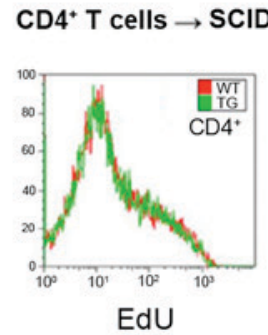

B
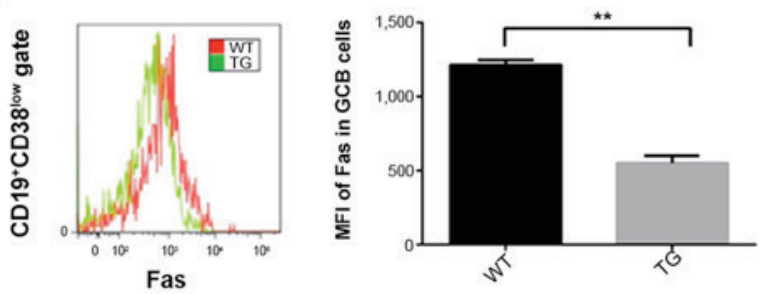

E
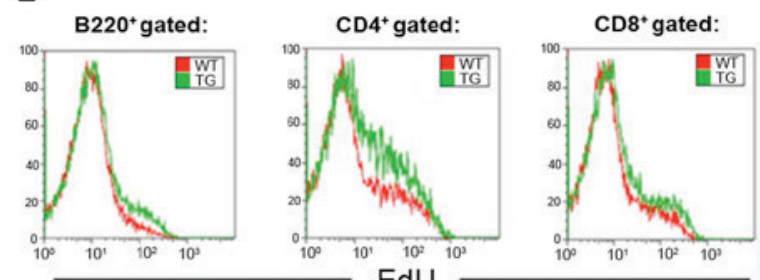

EdU

WT non-GCB + WTT cells $\rightarrow$ SCID

TG non-GCB + WTT cells $\rightarrow$ SCID

Figure 5. miR-21 promotes homeostatic proliferation of lymphocytes. (A) Proliferation of B cells was detected at 7 days after adoptive transfer. (B) Fas was downregulated in the GCB cells of the recipient mice and proliferation of the $\mathrm{CD} 4^{+} \mathrm{T}$ cells was detected at 7 days after adoptive transfer. (C) B cells were cultured in vitro for $72 \mathrm{~h}$ under the stimulation of the in vitro proliferation experiment. The CFSE dilution method was used to analyze the cell proliferation. (D) Proliferation of T cells was detected at 7 days after adoptive transfer. (E) Non-GCB cells stemmed from the transgenic and wild-type mice. They were mixed with the T and B cells that stemmed from the wild-type mice respectively and transferred to the SCID mice in an adoptive manner. Homeostatic proliferation of $\mathrm{T}$ and $\mathrm{B}$ cells of the wild-type mice was detected. ${ }^{* *} \mathrm{P}<0.01$.

downregulation are the major causes for ALPS onset (26). Here, we demonstrated that miR-21 overexpression can downregulate the Fas expression in the GCB cells and finally lead to ALPS in transgenic mice. However, in transgenic mice, Fas dysfunction occurs in B cells with highly-expressed miR-21.
In our transgenic mice, a decrease in Fas expression on the surface of the natural B cells allowed an easy transformation into GCB cells. It seems that Fas downregulation in GCB cells may disturb lymphocyte homeostasis and excessive lymphoid hyperplasia. Furthermore, Fas downregulation in GCB cells 
can promote the survival of mature T cells. Usually, activated $\mathrm{T}$ cells lose their CD4 or CD8 co-receptors, therefore an accumulation in DNT cells may occur. These observations supported the idea that miR-21 is involved in ALPS pathogenesis and may provide a new explanation of ALPS pathogenesis, particularly in cases with viral infection and chronic inflammation. We believe that the miR-21 deficient mice experienced an autoimmune disease similar to ALPS.

\section{References}

1. Halász T, Horváth G, Pár G, Werling K, Kiss A, Schaff Z and Lendvai G: miR-122 negatively correlates with liver fibrosis as detected by histology and FibroScan. World J Gastroenterol 21: 7814-7823, 2015.

2. Croci S, Zerbini A, Boiardi L, Muratore F, Bisagni A, Nicoli D, Farnetti E, Pazzola G, Cimino L, Moramarco A, et al: MicroRNA markers of inflammation and remodelling in temporal arteries from patients with giant cell arteritis. Ann Rheum Dis 20: 7846, 2015

3. Punga AR, Andersson M, Alimohammadi M and Punga T: Disease specific signature of circulating miR-150-5p and miR-21-5p in myasthenia gravis patients. J Neurol Sci 356: 90-96, 2015.

4. Wu XN, Ye YX, Niu JW, Li Y, Li X, You X, Chen H, Zhao LD, Zeng XF, Zhang FC, et al: Defective PTEN regulation contributes to $\mathrm{B}$ cell hyperresponsiveness in systemic lupus erythematosus. Sci Transl Med 6: 246ra99, 2014.

5. Quinn SR and O'Neill LA: The role of microRNAs in the control and mechanism of action of IL-10. Curr Top Microbiol Immunol 380: 145-155, 2014

6. Ma X, Zhou J, Zhong Y, Jiang L, Mu P, Li Y, Singh N, Nagarkatti $M$ and Nagarkatti P: Expression, regulation and function of microRNAs in multiple sclerosis. Int J Med Sci 11: 810-818, 2014.

7. Tang ZM, Fang M, Wang JP, Cai PC, Wang P and Hu LH: Clinical relevance of plasma miR-21 in new-onset systemic lupus erythematosus patients. J Clin Lab Anal 28: 446-451, 2014.

8. Haider BA, Baras AS, McCall MN, Hertel JA, Cornish TC and Halushka MK: A critical evaluation of microRNA biomarkers in non-neoplastic disease. PLoS One 9: e89565, 2014.

9. Smigielska-Czepiel K, van den Berg A, Jellema P, van der Lei RJ, Bijzet J, Kluiver J, Boots AM, Brouwer E and Kroesen BJ: Comprehensive analysis of miRNA expression in T-cell subsets of rheumatoid arthritis patients reveals defined signatures of naive and memory Tregs. Genes Immun 15: 115-125, 2014.

10. Chafin CB, Regna NL, Hammond SE and Reilly CM: Cellular and urinary microRNA alterations in NZB/W mice with hydroxychloroquine or prednisone treatment. Int Immunopharmacol 17: 894-906, 2013

11. Bao H, Hu S, Zhang C, Shi S, Qin W, Zeng C, Zen K and Liu Z: Inhibition of miRNA-21 prevents fibrogenic activation in podocytes and tubular cells in $\operatorname{IgA}$ nephropathy. Biochem Biophys Res Commun 444: 455-460, 2014.

12. Wang H, Peng W, Ouyang X, Li W and Dai Y: Circulating microRNAs as candidate biomarkers in patients with systemic lupus erythematosus. Transl Res 160: 198-206, 2012.

13. Mycko MP, Cichalewska M, Machlanska A, Cwiklinska H, Mariasiewicz M and Selmaj KW: MicroRNA-301a regulation of a T-helper 17 immune response controls autoimmune demyelination. Proc Natl Acad Sci USA 109: E1248-E1257, 2012.
14. Stagakis E, Bertsias G, Verginis P, Nakou M, Hatziapostolou M, Kritikos H, Iliopoulos D and Boumpas DT: Identification of novel microRNA signatures linked to human lupus disease activity and pathogenesis: miR-21 regulates aberrant $\mathrm{T}$ cell responses through regulation of PDCD4 expression. Ann Rheum Dis 70: 1496-1506, 2011

15. Pan W, Zhu S, Yuan M, Cui H, Wang L, Luo X, Li J, Zhou H, Tang $Y$ and Shen N: MicroRNA-21 and microRNA-148a contribute to DNA hypomethylation in lupus $\mathrm{CD} 4^{+} \mathrm{T}$ cells by directly and indirectly targeting DNA methyltransferase 1 . J Immunol 184: 6773-6781, 2010.

16. Ruan Q, Wang T, Kameswaran V, Wei Q, Johnson DS, Matschinsky F, Shi W and Chen YH: The microRNA-21-PDCD4 axis prevents type 1 diabetes by blocking pancreatic beta cell death. Proc Natl Acad Sci USA 108: 12030-12035, 2011.

17. Bostjancic E and Glavac D: Importance of microRNAs in skin morphogenesis and diseases. Acta Dermatovenerol Alp Pannonica Adriat 17: 95-102, 2008.

18. Alisi A, Da Sacco L, Bruscalupi G, Piemonte F, Panera N, De Vito R, Leoni S, Bottazzo GF, Masotti A and Nobili V: Mirnome analysis reveals novel molecular determinants in the pathogenesis of diet-induced nonalcoholic fatty liver disease. Lab Invest 91: 283-293, 2011.

19. Dey N, Das F, Mariappan MM, Mandal CC, Ghosh-Choudhury N, Kasinath BS and Choudhury GG: MicroRNA-21 orchestrates high glucose-induced signals to TOR complex 1, resulting in renal cell pathology in diabetes. J Biol Chem 286: 25586-25603, 2011.

20. Bergman P, James T, Kular L, Ruhrmann S, Kramarova T, Kvist A, Supic G, Gillett A, Pivarcsi A and Jagodic M: Next-generation sequencing identifies microRNAs that associate with pathogenic autoimmune neuroinflammation in rats. J Immunol 190: 4066-4075, 2013.

21. Fognani E, Giannini C, Piluso A, Gragnani L, Monti M, Caini P, Ranieri J, Urraro T, Triboli E, Laffi G, et al: Role of microRNA profile modifications in hepatitis $\mathrm{C}$ virus-related mixed cryoglobulinemia. PLoS One 8: e62965, 2013.

22. Xu WD, Pan HF, Li JH and Ye DQ: MicroRNA-21 with therapeutic potential in autoimmune diseases. Expert Opin Ther Targets 17: 659-665, 2013.

23. Koelsch KA, Webb R, Jeffries M, Dozmorov MG, Frank MB, Guthridge JM, James JA, Wren JD and Sawalha AH: Functional characterization of the MECP2/IRAK1 lupus risk haplotype in human T cells and a human MECP2 transgenic mouse. J Autoimmun 41: 168-174, 2013.

24. Kimura J, Ichii O, Miyazono K, Nakamura T, Horino T, Otsuka-Kanazawa S and Kon Y: Overexpression of Toll-like receptor 8 correlates with the progression of podocyte injury in murine autoimmune glomerulonephritis. Sci Rep 4: 7290, 2014.

25. Dong L, Wang X, Tan J, Li H, Qian W, Chen J, Chen Q, Wang J, $\mathrm{Xu} \mathrm{W}$, Tao C, et al: Decreased expression of microRNA-21 correlates with the imbalance of Th17 and Treg cells in patients with rheumatoid arthritis. J Cell Mol Med 18: 2213-2224, 2014.

26. van der Geest KS, Smigielska-Czepiel K, Park JA, Abdulahad WH, Kim HW, Kroesen BJ, van den Berg A, Boots AM, Lee EB and Brouwer E: SF Treg cells transcribing high levels of Bcl-2 and microRNA-21 demonstrate limited apoptosis in RA. Rheumatology (Oxford) 54: 950-958, 2015. 